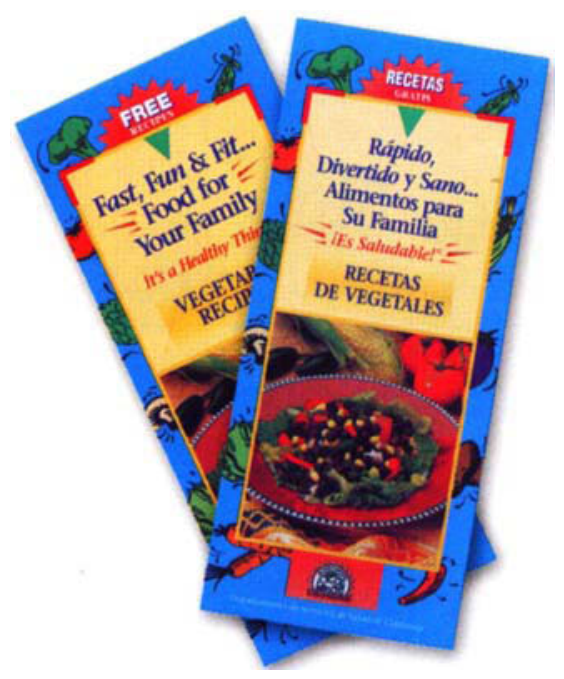

A 1997 random survey of 2,000 participants in the U.S. Department of Agriculture's WIC Farmers' Market Nutrition Program found that the program helped motivate low-income, pregnant and breast-feeding mothers to buy (and eat) fresh fruits and vegetables from farmers' markets. In California, the program provides $\$ 20$ in coupons to participants in the Special Supplemental Nutrition Program for Women, Infants and Children (WIC). We found a small but statistically significant increase in fruit and vegetable consumption among survey respondents. The total intake was 4.50 servings per day in the group that used coupons compared with 3.56 in the group that did not, an increase of almost 1 serving. Participants were also enthusiastic about returning to farmers' markets. Sixty-two percent of those who were given coupons used them. Most participants wanted to see the program expanded although many responded with suggestions to improve it.

$\mathrm{T}$ he WIC Farmers' Market Nutrition Program (FMNP) was established by the U.S. Department of Agriculture (USDA) in 1992 to encourage participants in the Special Supplemental Nutrition Program for Women, Infants

\title{
USDA program stimulates interest in farmers' markets among low-income women
}

\author{
Amy Block Joy $\square$ Sybille Bunch $\sqcup$ Maradee Davis $\sqsupset \quad$ Jody Fujii
}

and Children (WIC) to include more fresh fruits and vegetables in their diets, and to shop more frequently at farmers' markets (USDA 1996).

Administered by USDA's Food and Nutrition Service, the program offers coupons to purchase fresh, locally grown fruits and vegetables from farmers' markets. FMNP is considered a success. Nationally, the average coupon benefit was $\$ 13.02$ per participating household in 1997. In 1997, USDA provided $\$ 7.28$ million dollars for the program, reaching 1,345 farmers' markets, 9,161 farmers and nearly 1.1 million WIC participants in 30 states.

The program began operating in California in 1994 with a federal cash grant and nonfederal matching funds of at least 30\%. In 1997, California received $\$ 164,228$ from USDA for FMNP. In California, the coupons are given to a highrisk subgroup of WIC recipients, defined as pregnant and/or breast-feeding mothers and their children. Each California participant was given $\$ 20$ in coupons (in $\$ 1$ denominations). The program is now administered through the California WIC program in the Department of Health Services.

We conducted a random, stratified survey of FMNP participants concerning their fruit and vegetable consumption practices and views of the program. Of 10,991 WIC clients (out of 61,061 total statewide) who received coupons in 1997, completed the surveys and were considered for inclusion in the random sample, we analyzed $18 \%$ or 2,000 responses.

\section{Survey of WIC-FMNP participants}

According to USDA (1996), a farmers' market is "an association of local farmers who assemble at a defined location for the purpose of selling their produce directly to consumers." California FMNP offered the program to WIC clinics located near farmers' markets throughout California (26 WIC clinics in 16 counties, both urban and rural). WIC clinic staff were required to: (1) attend program training; (2) provide FMNP coupons to high-risk women; (3) keep track of coupon usage; (4) provide nutrition education related to FMNP goals; and (5) evaluate a sample of the recipients. Our results help to fulfill the fifth requirement to evaluate a sample of recipients.

From June through September 1997, participants could use coupons only at authorized farmers' markets. Eligible markets were those that agreed to coupon use, were accessible to WIC clients and would follow USDA regulations (table 1).

Initial survey and lesson. The survey was developed and designed on the basis of previous work by UC researchers (Davis et al. 1997; Joy et al. 1996). The initial survey contained 17 questions relating to demographics, experience shopping at farmers' markets, number of servings of fruits and vegetables consumed the previous day and, finally, two open-ended questions requesting feedback.

The WIC nutritionist screened WIC clients and selected pregnant and/or breast-feeding women who agreed to be part of the survey. Each participant 


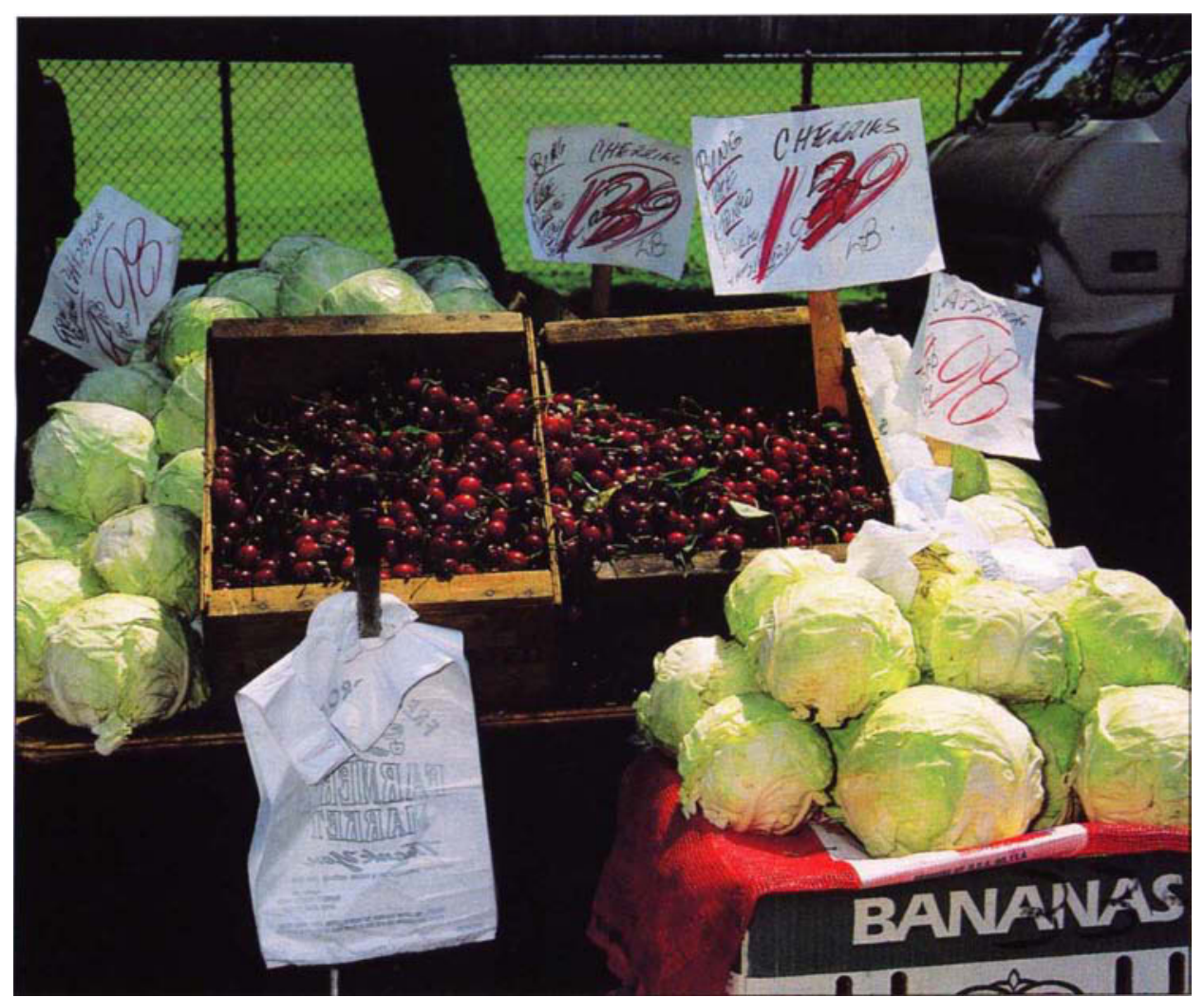

took the initial 5-to-10 minute survey, which was self-administered on paper. The survey was offered in English, Spanish, Chinese, Vietnamese and Hmong. The WIC nutritionist kept the completed surveys in each client's file.

Participants received a 30 -minute nutrition lesson, which varied from site to site and was based on decisions made at the local WIC clinic. The WIC nutritionist presented the lesson either individually or in small groups (with between two and 20 participants) waiting to receive the coupons. Clinic staff used a variety of materials developed for the program, including a slide set, videotape and handouts.

Generally, the content of the lesson contained information on the dietary importance of fresh fruits and vegetables and the nutritional value of specific fruits and vegetables, in terms of vitamins, minerals, fiber and the absence of fat. Finally, ways to prepare, serve and store fresh fruit and vegetables were presented.

Clients were then given 20 coupons worth $\$ 20$ and the hours of operation and directions to the authorized local farmers' market, using either private or public transportation.
Follow-up survey. The follow-up when the client returned for the next WIC clinic visit. The one-page survey, pilot-tested for 2 years, was also self-administered.

The follow-up survey was based on documentation required by USDA (1996) with other questions added. It contained 17 questions, including these questions of interest to the survey was given 1 month later

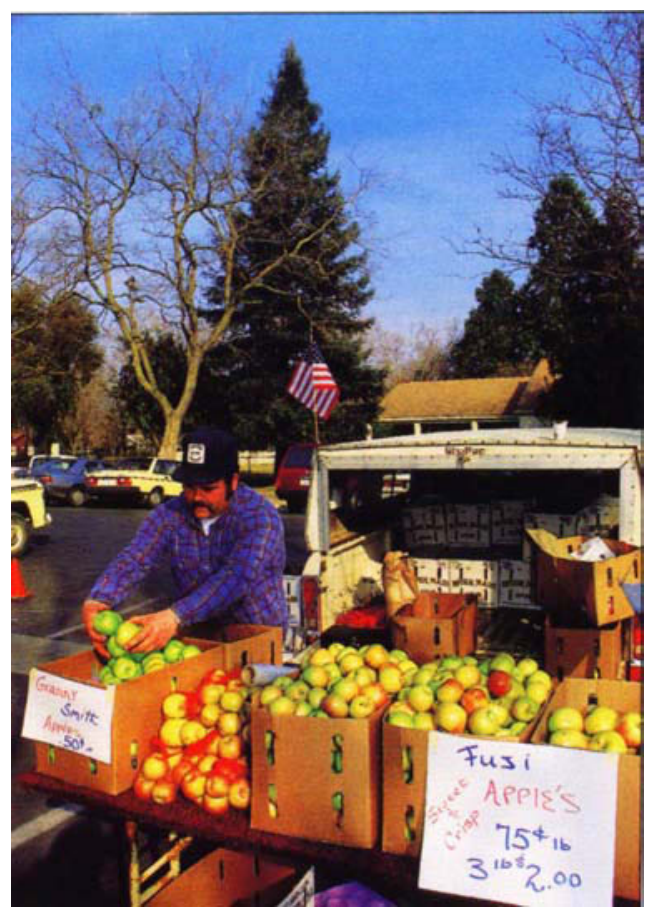

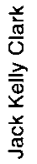

In California, the USDA Farmers' Market Nutrition Program provides $\$ 20$ in cou․ pons for low-income women who were of pregnant or breast-feeding, to spend at authorized farmers' markets. Program participants receive nutrition lessons and directions to nearby markets.

USDA: (1) Is this the first year participating in the FMNP? (2) Did FMNP encourage you to eat more fresh fruits and vegetables? (3) Do you plan to eat more fruits and vegetables? (4) Did you learn new ways to prepare or cook fresh fruits and vegetables? (5) Will you continue to shop at farmers' markets even without coupons to spend there? (6) Did you learn a new way to store fresh fruits and vegetables

TABLE 1. USDA's FMNP regulations (partial list)

\begin{tabular}{|c|c|}
\hline Allowable & Not allowable \\
\hline $\begin{array}{l}\text { Recipients must be women, infants over } 4 \text { months } \\
\text { or a child who receives WIC benefits. }\end{array}$ & $\begin{array}{l}\text { Ineligible foods include cider, juices, honey, maple } \\
\text { syrup, seeds, nuts, eggs, meat, cheese, seafood, } \\
\text { flowers, ornamental produce and foods grown out- } \\
\text { side the United States. }\end{array}$ \\
\hline $\begin{array}{l}\text { Coupon value (per recipient, per year) must be be- } \\
\text { tween } \$ 10 \text { and } \$ 20 \text {, allocated to either individuals } \\
\text { or households. }\end{array}$ & $\begin{array}{l}\text { Unauthorized farmers' markets cannot accept } \\
\text { FMNP coupons. Participating farmers' markets } \\
\text { must display a sign stating that they are authorized } \\
\text { to redeem coupons. }\end{array}$ \\
\hline Nutrition education is required. & Sales tax cannot be collected. \\
\hline $\begin{array}{l}\text { Farmers must be trained in FMNP procedures, } \\
\text { agree to be monitored, display sign, accept cou- } \\
\text { pons within the dates at the current price or less, } \\
\text { and assure that FMNP coupons are redeemed only } \\
\text { for eligible foods. They may not discriminate against } \\
\text { coupon users. Farmers may accept cash in addition } \\
\text { to coupons. }\end{array}$ & $\begin{array}{l}\text { Cash change can not be provided for purchases } \\
\text { less than the amount of the coupons. If the amount } \\
\text { of sale is less than the amount on the coupon, addi- } \\
\text { tional fruits and vegetables can be added to make } \\
\text { up the difference. } \\
\text { Torn coupons or those lacking a coupon number } \\
\text { can not be redeemed. }\end{array}$ \\
\hline
\end{tabular}




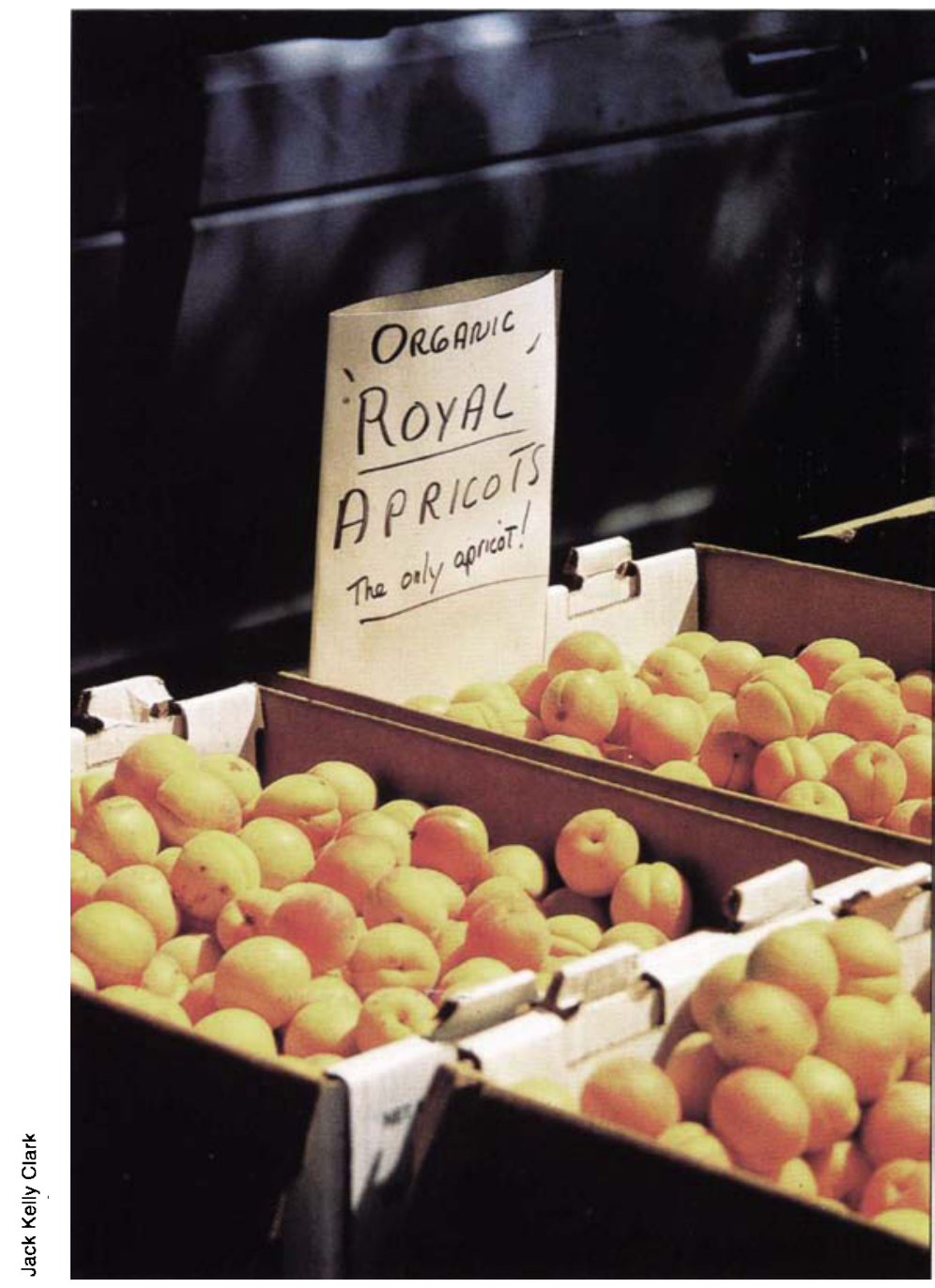

In a survey of 2,000 Farmers' Market Nutrition Program participants, $58 \%$ said the quality of fruits and vegetables was better than at the grocery store.

to keep them from spoiling? and (7) Did you buy a new fresh fruit or vegetable that you had never tried before?

Of interest to UC researchers, the survey also asked: (8) Did you spend cash or food stamps in addition to the coupons? and (9) What was the quality of food at the farmers' market?

The other questions collected demographic information, including ethnicity, age and number of children

A stratified, random sample procedure was used to determine which surveys to analyze. In this way, there was no bias in the analysis from places where coupon usage was either higher or lower than anticipated. Data from both general linear model surveys were analyzed at UC Davis using SAS (Version 6.12, ANOVA, 1996). Client names and addresses did not appear on the forms and all data were confidential.

\section{Program participation}

Farmers' markets. In 1997, 51 California farmers' markets (including 2,183 farmers) participated in the FMNP program, which served 26 WIC sites in 16 California counties. USDA provided $\$ 164,228$ for FMNP in California in 1997, resulting in the distribution of sets of $\$ 20$ in coupons to 10,991 women. Of the total distribution, 6,867 women $(62 \%)$ redeemed all their coupons. Federal regulations do not allow vendors to give cash change for the coupons. Instead of cash change, farmers were asked to give coupon holders additional fruits and vegetables (table 1).

TABLE 2. Fruit and vegetable intake per day among 1997 Farmers' Market Nutrition Program participants

\begin{tabular}{|c|c|c|c|c|c|c|}
\hline \multirow[b]{2}{*}{ Servings of } & \multicolumn{3}{|c|}{$\begin{array}{c}\text { Used farmers' market } \\
\text { at least once }\end{array}$} & \multicolumn{3}{|c|}{$\begin{array}{c}\text { Did not use } \\
\text { farmers' market }\end{array}$} \\
\hline & Number & Baseline & Follow-up & Number & Baseline & Follow-up \\
\hline Fruit & 1,343 & 2.39 & $2.49^{*}$ & 99 & 2.01 & 1.99 \\
\hline Vegetables & 1,288 & 1.92 & $2.01^{*}$ & 97 & 1.70 & 1.57 \\
\hline Total servings & & 4.31 & 4.50 & & 3.71 & 3.56 \\
\hline
\end{tabular}

-Difference from baseline to follow-up is significant $(P<0.05)$.

Clients could use food stamps and cash in addition to the FMNP coupons.

Demographics. The 2,000 survey respondents represented a cross-section of ethnic groups, with the majority of clients being Hispanic $(67.5 \%)$. The rest were Caucasian $(10.6 \%)$, black $(9.0 \%)$, Asian $(7.7 \%)$, Native American (2.1\%) or other $(3.1 \%)$. The average client was 26 years old; $1,556(78 \%)$ were pregnant, $1,168(58 \%)$ were breast-feeding and some were both.

Program participation. Among the 2,000 survey respondents, $1,845(92 \%)$ said this was their first experience receiving FMNP coupons. Of those, 272 $(15 \%)$ had previously visited a farmers' market.

Fruit and vegetable intake.

Among respondents who visited a farmers' market at least once during $1997,1,343(67 \%)$ reported results on fruit consumption and $1,283(64 \%)$ reported their vegetable consumption (table 2). The sample of respondents who did not use the coupons before the follow-up survey served as a control. Ninety-nine survey participants reported that they consumed fruit and 97 consumed vegetables, but they did not obtain them at the farmer's market or with FMNP coupons.

Those who used the farmers' market increased their average servings of fruit $4.2 \%$ per day and vegetables $14.7 \%$ per day (table 2 ). The increase in fruit from baseline to follow-up was small ( 0.1 serving) and similar for vegetables ( 0.09 servings), but the increase was statistically significant. For the groups that did not use the coupons, intakes decreased in both fruits by $1.0 \%$ and vegetables by $7.6 \%$, although the change was not significant. The total intake of fruits and vegetables was 4.50 servings per day in the group that used coupons compared with 3.56 in the group that did not use coupons, an increase of almost 1 serving.

Shopping practices. Among respondents, $58.2 \%$ said the quality at the farmers' market was better than that at the grocery store. Fifty-one percent said they spent their own cash, $11.7 \%$ used food stamps and $10.7 \%$ used both, in addition to FMNP coupons (table 3 ). 
Comparison with national data. California's survey results were above national averages (NAFMNP 1998). The coupon redemption rate in California was $62 \%$ compared with the national average of $60 \%$. Eighty-five percent of WIC participants surveyed in California ate more fresh fruits and vegetables after participating in FMNP, compared with $73 \%$ nationally.

In addition, $73 \%$ of California recipients used cash and/or food stamps with the FMNP coupons, compared with $51 \%$ nationally. Finally, $85 \%$ of California participants reported that this was their first time visiting a farmers' market, compared with the national average of $59 \%$.

\section{Program spurred enthusiasm}

Our most important finding was that FMNP helped low-income women, many of whom had never shopped at a farmers' market before, to go to a farmers' market, purchase fruits and vegetables and eat them. Many were enthusiastic about shopping at the farmers' market again. For example, more than half $(56 \%)$ of survey participants said they tried a new fruit or vegetable while shopping with FMNP coupons, $56.2 \%$ reported that they bought more fruits and vegetables, and $84.5 \%$ reported that they ate more fruits and vegetables (table 3 ).

Answers to the open-ended survey questions about the women's experience with the program contained many enthusiastic comments handwritten by survey respondents in Sacramento, Chico, Long Beach,

TABLE 3. Respondents who checked "yes" to questions about Farmers' Market Nutrition Program in 1997 survey

\begin{tabular}{ll}
\hline Because of FMNP, I now: & $\%$ \\
\hline Eat more fruits and vegetables & 84.5 \\
Plan to eat more fruits and vegetables & 93.6 \\
Will continue to shop at farmers' market & 76.4 \\
Bought more fruits and vegetables & 56.2 \\
Learned new ways to prepare fruits & 62.4 \\
$\quad$ and vegetables & 58.2 \\
Quality better than store & 65.5 \\
Leamed new ways to store & 51.0 \\
Used cash, in addition to coupons & 11.7 \\
Used food stamps & 10.7 \\
Used both & 73.0 \\
\hline Used cash and/or food stamps &
\end{tabular}

Irwindale (near Santa Barbara), San Francisco and Vacaville. For example, they said: "The coupons were easy to use, the program was helpful to me, and my kids enjoyed the fruits and vegetables"; "I did not run out of food the month I had the coupons"; and "I wish the farmers' markets were open 2 days a week instead of only once a week."

\section{Suggestions to improve program}

While many survey respondents expressed enthusiasm for the coupons and nutrition education, they also provided suggestions for improvement. One survey respondent reported feeling embarrassed because the coupons' bright color drew unwanted attention, resulting in the feeling that "I thought people knew I was poor." In earlier years, coupons were printed in one bright color for each year so that vendors could easily spot coupons from previous years. Currently, checks are used instead. The theme of self-consciousness turned up in another comment when the woman reported that she didn't want to have to ask vendors about taking the coupons.

Several women asked for improvements in the location and operating times of the farmers' markets. One suggested that more farmers' markets are needed "because I had to take a bus across town to get to the one that used the coupons," while another asked that the markets stay open longer, as "it is hard to get there before 1 p.m."

Another respondent suggested that the program distribute more coupons and in smaller amounts, "so I can try different fruits and vegetables."

The health benefits of consuming fresh fruits and vegetables are well documented. They are associated with a lower risk for chronic disease, including some forms of cancer and heart disease (Block et al. 1992; Subar et al. 1995). Offering fresh fruits and vegetables to families with young children has the additional benefit of introducing children to a positive dietary influence at an early age. At the same time, farmers benefit from the FMNP because their fresh produce reaches a new market. Because only $15 \%$ of FMNP families had previously visited a farmers' market, there is a large potential audience among high-risk families in California. By offering a way for agriculture and nutrition to work together, FMNP illustrates how good nutrition and health promotion can begin with people eating fresh, locally grown produce.

A.B. Joy is Specialist and S. Bunch is Research Associate, Department of Nutrition, UC Davis; M. Davis is Professor, Department of Epidemiology, UC San Francisco; and J. Fujii is Chief of Staff, Sacramento Office of Senator Michael Machado. We received assistance with processing and preparing the survey from: Mical Shilts, Graduate Student, UC Davis (data entry); Jim Mulroney, Administrative Assistant, UC Davis (report preparation); and GeNam Wong, WIC Program Specialist, USDA Food and $\mathrm{Nu}$ trition Service, San Francisco (program consultation). The authors gratefully acknowledge the WIC families for their participation; WIC clinic staff; and growers who sell their produce at farmers' markets. The study was funded in part by the U.S. Department of Agriculture.

\section{References}

Block G, Patterson B, Subar A. 1992 Fruits, vegetables and cancer prevention: $A$ review of the epidemiological evidence. Nutr Cancer 18:1-29.

Davis M, Fujii J, Joy AB, Bunch S. 1997. Survey Results from the 1996 Farmers' Market Nutrition Program of California, Final Report to the USDA/Expanded Food and Nutrition Education Program, UC Davis.

Joy AB, Davis M, Fujii J, Bunch S. 1996. Survey Results from the 1995 Farmers' Market Nutrition Program of California, Final Report to USDAVEFEP, UC Davis.

[NAFMNP] National Association of Farmers' Market Nutrition Programs. 1998. Program Impact Report for the 1997 WIC Farmers' Market Nutrition Program. Washington, DC.

Subar AS, Heimendinger J, Patterson BH, et al. 1995. Fruit and vegetable intake in the United States: The baseline survey of the Five A Day for Better Health Program. Am J Health Prom 9(5):352-60.

[USDA] US Department of Agriculture. 1996. WIC Farmers' Market Nutrition Program. Consolidated Regulations: Food and Nutrition Service 7(CFR) 11:304-16. 